\title{
The Epidemiology of Low Birth Weight and Preterm Delivery, in Hawai i, 2000-2001
}

\author{
Cheryl B Prince, Limin Song, Nighat Quadri, Kathleen Kromer Baker
}

Hawai i Department of Health

\begin{abstract}
To create a better understanding of Hawai i's birthing population so that culturally appropriate strategies to prevent infant mortality could be developed, we undertook an analysis of population-based perinatal data collected in Hawai i for the years 2000 and 2001. The data were collected by the Pregnancy Risk Assessment Monitoring System (PRAMS). In this system, a stratified random sample of women who delivered a live born infant are mailed a self-administered questionnaire two to six months after they deliver, with telephone follow-up for those who do not respond. A bivariate analyses of maternal characteristics of singleton infants and the prevalence of low birth weight $(<2,500$ grams) and preterm delivery ( $<37$ weeks gestational age) at the time of PRAMS survey were conducted using chi-square test statistics. To assess the independent effects of the sociodemographic and behavioral variables on the outcome, we constructed logistic regression models adjusting for age, education, race/ethnicity, marital status, household income, area of residence, 1st trimester entry into prenatal care, 3rd trimester smoking or drinking alcohol, illegal drug use, and being the victim of physical abuse during the pregnancy. We estimated model coefficients by using unconditional maximum likelihood methods and we estimated relative risks by calculating adjusted odds ratios (aORs). A total of 6,251 women were sampled and 5,009 responded, for a response rate of $80 \%$. Most women (98.6\%) had some prenatal care, although nearly $20 \%$ entered care in the second or third trimester. Women who were less than 20 years of age (aOR 1.7; 95\% confidence interval [CI] 1.1-2.6) or had only a high school education (aOR 1.5; 95\% CI 1.1-2.0) were more likely to have delivered a low birth weight infant than were older more educated women. After adjustment, only women who were not married were more likely to have had a preterm delivery than were married women (aOR 1.5; 95\% CI 1.1-2.0). In conclusion, we found that risk factors for low birth weight and preterm delivery among singleton infants in Hawai i were not different from risk factors reported for mainland populations, namely maternal age, education and marital status. Hawai i PRAMS has been a valuable source of data about the women giving birth in Hawai i. Further analyses of these perinatal data should provide useful information for clinicians, policymakers and public health advocates.
\end{abstract}

(C) 2003 Californian Journal of Health Promotion. All rights reserved.

Keywords: low birth weight; preterm delivery; perinatal; epidemiology

\section{Introduction}

The leading causes of infant mortality in the U.S. today are congenital malformations and disorders related to short gestation (i.e., preterm delivery) and low birth weight (Miniño, Arias, Kochanek, Murphy, Smith, 2002). The causes of the majority of congenital defects are unknown, and thus, prevention strategies are difficult, if not impossible, to develop. Prior research has identified demographic risk markers and behavioral risk factors associated with preterm delivery (Ananth, Misra, Demissie, \& Smullian, 2001; Berkowitz \& Papiernik, 1993; Blackmore, Rowley, \& Kiely, 1994; CDC, 1999; Collins \& Hammond 1996; Pickett, Ahern, Selvin \& Abrams, 2002; Rolett \& Kiely, 2000). Furthermore, preterm delivery is the leading cause of low birth weight $(<2,500$ grams) (Blackmore, Rowley, \& Kiely, 1994; CDC, 1994; Kiely, Brett, Yu, \& Rowley, 1994) and the mortality associated with very low birth weight ( $<1,500$ grams) is nearly 25\% (Mathews, 
MacDorman, \& Menacker, 2002). To create a better understanding of Hawai ì's birthing population so that culturally appropriate strategies to prevent infant mortality could be developed, we undertook an analysis of population-based perinatal data collected in Hawai i for the years 2000 and 2001.

\section{Methods}

The data were collected by the Pregnancy Risk Assessment Monitoring System (PRAMS), which has been described in detail elsewhere (Colley Gilbert, Shulman, Fischer, \& Rogers, 1999). In this system, a stratified random sample of women who delivered a live born infant is drawn from the Hawai i birth certificate file. These women are mailed a self-administered questionnaire two to six months after they deliver, with telephone follow-up for those who do not respond. PRAMS has been approved by institutional review boards at both the federal (Centers for Disease Control and Prevention) and state levels. The mailed packet and telephone introductory script contain information on PRAMS, state its purpose and goals, and indicate that participation is voluntary. Informed consent is implied by completing the survey or agreeing to proceed with the interview.

Questions are asked about the peri-conceptional, prenatal, post-partum, and early child rearing behaviors and experiences of the mothers sampled. Hawai i PRAMS over-samples Native Hawaiian women and women living in rural areas outside of the urban center of Honolulu. The PRAMS data set contains questionnaire data, selected birth certificate information, and selected information on the timing and mode of data collection. The data are weighted by the Centers for Disease Control and Prevention (CDC), with adjustments made for the sampling design, and potential non-coverage and nonrespondent biases.
We conducted a descriptive analysis of Hawai $\mathrm{i}$ PRAMS for the years 2000-2001 using SUDAAN software to produce appropriate standard errors when calculating population estimates. A bivariate analyses of maternal characteristics of singleton infants and the prevalence of low birth weight $(<2,500$ grams) and preterm delivery ( $<37$ weeks gestational age) at the time of PRAMS survey were conducted using Chi-square test statistics. To assess the independent effects of the sociodemographic and behavioral variables on the outcome, we constructed logistic regression models adjusting for age, education, race/ethnicity, marital status, household income, area of residence, 1st trimester entry into prenatal care, 3rd trimester smoking or drinking alcohol, illegal drug use, and being the victim of physical abuse during the pregnancy. We estimated model coefficients by using unconditional maximum likelihood methods and we estimated relative risks by calculating adjusted odds ratios (aORs).

\section{Results}

A total of 6,251 women were sampled and 5,009 responded, for a response rate of $80 \%$. This sample is from an estimated 33,991 live births occurring during that time period. The mean birth weight of these infants was 3,300 grams, and their mean age at the time their mother responded to the survey was 124 days. Nearly one half $(48 \%)$ of the mothers having singleton live births in Hawai i were between the ages of 25 and 34 and had more than a high school education (49\%) (Table 1). The majority of women were married (68\%) and lived in urban Honolulu (50\%). The presence of modifiable risk factors ranged from a low of 3.1\% for use of illegal drugs in pregnancy to a high of $8.9 \%$ for third trimester smoking. Most women (98.6\%) had some prenatal care, although nearly $20 \%$ entered care in the second or third trimester. 
Table 1

Demographic \& Behavioral Characteristics of Resident Mothers with Singleton Live Births in Hawai i, PRAMS 2000-2001

\begin{tabular}{|c|c|}
\hline Characteristics & Percent* (weighted, n=33,991) \\
\hline \multicolumn{2}{|l|}{ Age } \\
\hline$<20$ & 10.3 \\
\hline $20-24$ & 24.9 \\
\hline $25-34$ & 48.0 \\
\hline$>34$ & 16.8 \\
\hline \multicolumn{2}{|l|}{ Education } \\
\hline$<12$ years & 9.5 \\
\hline 12 years & 41.4 \\
\hline$>12$ years & 49.0 \\
\hline \multicolumn{2}{|l|}{ Marital Status } \\
\hline Married & 67.7 \\
\hline Not Married & 32.3 \\
\hline \multicolumn{2}{|l|}{ Race/Ethnicity } \\
\hline Chinese \& Japanese & 16.2 \\
\hline Filipino & 20.7 \\
\hline Hawaiian/Part Hawaiian & 27.0 \\
\hline Other Asian and Pacific Islander & 9.4 \\
\hline Other Nonwhite & 4.1 \\
\hline White & 22.5 \\
\hline \multicolumn{2}{|l|}{ Residential Area } \\
\hline Urban Honolulu & 50.2 \\
\hline Rural Oahu & 23.7 \\
\hline Neighbor Islands & 26.1 \\
\hline \multicolumn{2}{|l|}{ Household Income } \\
\hline$<\$ 10,000$ & 14.4 \\
\hline$\$ 10,000-\$ 30,000$ & 31.9 \\
\hline$\$ 30,001-\$ 50,000$ & 25.0 \\
\hline$>\$ 50,000$ & 28.7 \\
\hline 3rd Trimester Smoker & 8.9 \\
\hline 3rd Trimester Alcohol Drinker & 4.6 \\
\hline Illegal Drugs During Pregnancy & 3.1 \\
\hline Physical Abuse Victim & 5.2 \\
\hline Late Entry into Prenatal Care & 19.0 \\
\hline No Prenatal Care & 1.4 \\
\hline
\end{tabular}

*Percentages may not add to 100.0 because of rounding.

Significant differences in mother's age, education, marital status, and whether or not she was a 3rd trimester alcohol drinker were associated with low birth weight (Table 2). Additionally, significant differences in the mother's age, race, and marital status were associated with preterm delivery. No significant differences in area of residence, household income, or whether the mother was a 3rd trimester smoker, used illegal drugs during her pregnancy, had been the victim of physical abuse during her pregnancy, or entered prenatal care in the first trimester were noted when either low birth weight or preterm delivery was the outcome examined. 
Table 2

Prevalence of Low Birth Weight and Preterm Delivery Among Singletons by Demographic \& Behavioral Characteristics of Mothers in Hawai i, PRAMS 2000-2001

\begin{tabular}{|c|c|c|}
\hline $\begin{array}{c}\text { Characteristics } \\
\text { (weighted, } n=33,991 \text { ) }\end{array}$ & $\begin{array}{l}\text { Low Birth Weight } 6.0 \% \\
\text { (weighted, } n=2,018 \text { ) }\end{array}$ & $\begin{array}{l}\text { Preterm Delivery } 8.0 \% \\
\text { (weighted, n=2,622) }\end{array}$ \\
\hline Age & ** & ** \\
\hline$<20$ & 11.2 & 11.3 \\
\hline $20-24$ & 5.9 & 8.3 \\
\hline $25-34$ & 4.9 & 6.4 \\
\hline$>34$ & 6.3 & 10.1 \\
\hline Education & ** & NS \\
\hline$<12$ years & 9.0 & 9.7 \\
\hline 12 years & 7.0 & 8.8 \\
\hline$>12$ years & 4.6 & 7.1 \\
\hline Race/Ethnicity & NS & * \\
\hline Chinese \& Japanese & 7.0 & 9.0 \\
\hline Filipino & 6.5 & 9.0 \\
\hline Hawaiian & 6.7 & 9.0 \\
\hline Other Asian and Pacific Islander & 5.0 & 6.3 \\
\hline Other Nonwhite & 7.8 & 8.6 \\
\hline White & 4.2 & 5.9 \\
\hline Marital Status & $* * *$ & $* * *$ \\
\hline Married & 5.0 & 6.9 \\
\hline Not Married & 8.1 & 10.4 \\
\hline Residential Area & NS & NS \\
\hline Urban Honolulu & 5.7 & 8.2 \\
\hline Rural Oahu & 6.0 & 8.4 \\
\hline Neighbor Islands & 6.6 & 7.3 \\
\hline Household Income & NS & NS \\
\hline$<\$ 10,000$ & 6.9 & 10.1 \\
\hline$\$ 10,000-\$ 30,000$ & 6.3 & 7.7 \\
\hline$\$ 30,001-\$ 50,000$ & 5.1 & 6.7 \\
\hline$>\$ 50,000$ & 5.6 & 8.3 \\
\hline 3rd Trimester Smoker & NS & NS \\
\hline Yes & 8.1 & 10.2 \\
\hline No & 5.8 & 7.7 \\
\hline 3rd Trimester Alcohol Drinker & $* *$ & NS \\
\hline Yes & 3.3 & 5.5 \\
\hline No & 6.1 & 8.1 \\
\hline Illegal Drugs During Pregnancy & NS & NS \\
\hline Yes & 10.2 & 12.8 \\
\hline No & 5.8 & 7.9 \\
\hline Physical Abuse Victim & NS & NS \\
\hline Yes & 9.2 & 10.2 \\
\hline No & 5.8 & 7.9 \\
\hline 1st Trimester Prenatal Care & NS & NS \\
\hline Yes & 5.5 & 7.6 \\
\hline No & 7.5 & 9.1 \\
\hline No Prenatal Care & 15.1 & 20.3 \\
\hline
\end{tabular}

N.S. $=$ not significant; ${ }^{*} \mathrm{p}<0.05 ;{ }^{* *} \mathrm{p}<0.01 ;{ }^{* * *} \mathrm{p}<0.001$ 
We entered maternal age, education, marital status, and 3rd trimester alcohol drinking in a logistic regression model with low birth weight as the outcome (Table 3). Women who were less than 20 years of age (aOR 1.7; 95\% confidence interval [CI] 1.1-2.6) or had only a high school education (aOR 1.5; 95\% CI 1.12.0) were more likely to have delivered a low birth weight infant than were older more educated women.
We entered maternal age, maternal race, and marital status in a logistic regression model with preterm delivery as the outcome (Table 4). After adjustment, only women who were not married were more likely to have had a preterm delivery than were married women (aOR 1.5; 95\% CI 1.1-2.0).

Table 3

Logistic Regression Model of Risk Factors for Low Birth Weight in Hawai i, PRAMS 2000-2001

\begin{tabular}{|c|c|c|}
\hline \multicolumn{1}{|c|}{ Exposure } & Odds Ratio & 95\% Confidence Interval \\
\hline Age & & \\
\hline$<20$ & 1.7 & $1.1-2.6$ \\
\hline $20-24$ & 1.0 & --- \\
\hline $25-34$ & 0.9 & $0.7-1.3$ \\
\hline$>34$ & 1.4 & $0.9-2.1$ \\
\hline Education & & $0.9-2.3$ \\
\hline$<12$ years & 1.4 & $1.1-2.0$ \\
\hline 12 years & 1.5 & --- \\
\hline$>12$ years & 1.0 & --- \\
\hline Martial Status & & $0.9-1.8$ \\
\hline Married & 1.0 & \\
\hline Not Married & 1.3 & $0.3-1.0$ \\
\hline 3rd Trimester Alcohol Drinker & & --- \\
\hline Yes & 0.6 & 1.0 \\
\hline No & & \\
\hline
\end{tabular}

Table 4

Logistic Regression Model of Risk Factors for Preterm Delivery in Hawai i, PRAMS 2000-2001

\begin{tabular}{|l|c|c|}
\hline \multicolumn{1}{|c|}{ Exposure } & Odds Ratio & 95\% Confidence Interval \\
\hline Age & & \\
\hline$<20$ & 1.2 & $0.8-1.8$ \\
\hline $20-24$ & 1.0 & --- \\
\hline $25-34$ & 0.9 & $0.6-1.2$ \\
\hline$>34$ & 1.4 & $1.0-2.0$ \\
\hline Race/Ethnicity & & \\
\hline Chinese \& Japanese & 1.5 & $1.0-2.3$ \\
\hline Filipino & 1.4 & $1.0-2.2$ \\
\hline Hawaiian & 1.3 & $0.9-1.9$ \\
\hline Other Asian and Pacific Islander & 1.0 & $0.5-1.8$ \\
\hline Other Nonwhite & 1.5 & $0.8-2.9$ \\
\hline White & 1.0 & --- \\
\hline Marital Status & & \\
\hline Married & 1.0 & --- \\
\hline Not Married & 1.5 & $1.1-2.0$ \\
\hline
\end{tabular}




\section{Discussion}

The review of perinatal data among singletons born in Hawai i revealed several interesting results. Although teenage women were found to be at increased risk of delivering a low birth weight infant, this risk was not associated with preterm delivery. Often in maternal and child health programs, the youngest mothers, notably teenagers, are at the highest risk for adverse reproductive and parenting outcomes (Ventura, Curtin, \& Mathews, 1998). Our findings for low birth weight infants were consistent with previously reported research indicating that younger (Felice et al., 1981; Schwartz, 1990) and less educated (Elfbein \& Felice, 2003) women are more likely to deliver a low birth weight infant than their counterparts.

The increased risk of preterm delivery for unmarried women in Hawai $\mathrm{i}$ is consistent with national data (CDC, 1999; Rolett \& Kiely 2000). We speculate that this increased risk may be associated with increased experiences of stressful life events by single women as recently noted by Whitehead and colleagues (2003). These researchers had shown a relation between stressful life events and preterm delivery in an earlier study (Whitehead, Hill, Brogan \& Blackmore-Prince, 2002).

Although in our study most of the non-White ethnic groups were also shown to have increased risks of preterm delivery, none of these risks were statistically significant. Blackmore and colleagues (1993) have suggested that "race is a marker for stress but is not in itself a risk factor for preterm delivery".

This study has several strengths not usually found in studies of perinatal events. The study sample was population-based so the study results can be generalized to all women having live births of single infants in Hawaìi. Furthermore, some demographic information was available for all sampled women, and there were few demographic differences between sampled women and respondents, reducing the likelihood of non-response bias.

Nevertheless, this study also has some limitations. We were surprised to note that third trimester smoking was not associated with the prevalence of low birth weight in our bivariate analysis, since the effects of smoking on birth weight have been well established previously (Kiely, Brett, Yu, \& Rowley, 1994; Kleinman \& Madans, 1985). Moreover, even though Native Hawaiian women were over-sampled, it is likely that our total sample was not of sufficient size to demonstrate statistically significant differences among six different racial/ethnic groups. The information on behaviors during pregnancy is self-reported and was reported retrospectively. Women may have under-reported sensitive behaviors. The tendency to under-report socially unacceptable behaviors is mitigated somewhat, since most of the questionnaires were self-administered, which usually yields higher reporting of sensitive behaviors than telephone or face-to-face interviews (Aquilino 1994; Krysan, Schuman, Scott, \& Beatty, 1994; Tourangeau \& Smith, 1996).

In conclusion, we found that risk factors for low birth weight and preterm delivery among singleton infants in Hawai i were not different from risk factors reported for mainland populations, namely maternal age, education and marital status. Hawai i PRAMS has been a valuable source of data about the women giving birth in Hawai i. Further analyses of these perinatal data should provide useful information for clinicians, policymakers and public health advocates.

\section{References}

Ananth, C. V., Misra, D. P., Demissie, K., Smulian, J. C. (2001). Rates of preterm delivery among black women and white women in the United States over two decades: an age-period-cohort analysis. American Journal of Epidemiology;154, 657-665.

Aquilino, W. S. (1994). Interview mode effects in surveys of drug and alcohol use. Public Opinion Quarterly, 58, 210-240.

Berkowitz, G. S., and Papiernik, E. (1993). Epidemiology of preterm birth. Epidemiology Reviews, 15, 414-443. 
Blackmore, C. A., Ferré, C. D., Rowley, D. L., Hogue, C. J. R., Gaiter, J., Atrash, H. (1993). Is race a risk factor or a risk marker for preterm delivery? Ethnicity and Disease, 3, 372-377.

Blackmore, C. A., Rowley, D. L., Kiely, J. L. (1994). Preterm birth. In Centers for Disease Control and Prevention, From data to action: CDC's public health surveillance for women, infants, and children. Atlanta: U.S. Department of Health and Human Services, Public Health Service, Centers for Disease Control and Prevention, pp. 179-183.

Colley Gilbert. B. J., Shulman, H. B., Fischer, L., Rogers, M.M. (1999). The pregnancy risk assessment monitoring system (PRAMS): Methods and 1996 response rates from 11 states. Maternal and Child Health Journal; 3, 199-209.

Collins, J. W., and Hammond, N. A. (1996). Relation of maternal race to the risk of preterm, non-low birth weight infants: a population study. American Journal of Epidemiology, 143, 333-337.

Centers for Disease Control and Prevention. (1994). Increasing incidence of low birthweight - United States, 1981-1991. Morbidity and Mortality Weekly Report, 43, 335-339.

Centers for Disease Control and Prevention. (1999). Preterm singleton births - United States, 1989-1996. Morbidity and Mortality Weekly Report, 48, 185-189.

Elfenbein, D. S., and Felice, M. E. (2003). Adolescent pregnancy. Pediatric Clinics of North America, 50, 781-800.

Felice, M. E., Granados, J. L., Ances, I. G., Hebel, R., Roedor, L. M., Helad, F.P. (1981). The young pregnant teenager. Impact of comprehensive prenatal care. Journal of Adolescent Health Care, 1, 193-197.

Kiely, J. L., Brett, K. M., Yu, S., Rowley, D. L. (1994). Low birth weight and intrauterine growth retardation. In Centers for Disease Control and Prevention, From data to action: CDC's public health surveillance for women, infants, and children. Atlanta: U.S. Department of Health and Human Services, Public Health Service, Centers for Disease Control and Prevention, pp. 185202.

Kleinman, J. C., and Madans, J. H. (1985). The effects of maternal smoking, physical stature, and educational attainment of the incidence of low birth weight. American Journal of Epidemiology, 121, 843-855.

Krysan, M., Schuman, H., Scott, L. J., Beatty, P. (1994). Response rates and response content in mail versus face-to-face surveys. Public Opinion Quarterly, 58, 381-399.

Mathews, T. J., MacDorman, M. F., Menacker, F. (2002). Infant mortality statistics from the 1999 period linked birth/infant death data set. National Vital Statistics Reports; vol. 50, no. 4. Hyattsville, MD: National Center for Health Statistics.

Miniño, A. M., Arias, E., Kochanek, K. D., Murphy, S. L., Smith, B. L. (2002). Deaths: Final data for 2000. National vital statistics reports; vol. 50, no.15. Hyattsville, MD: National Center for Health Statistics.

Pickett, K. E., Ahern, J. E., Selvin, S., Abrams, B. (2002). Neighborhood socioeconomic status, maternal race and preterm delivery: a case-control study. Annals of Epidemiology, 12, 410-418.

Rolett, A., Kiely, J. L. (2000). Maternal sociodemographic characteristics as risk factors for preterm birth in twins versus singletons. Paediatric and Perinatal Epidemiology, 14, 211-218.

Schwartz, I. L. (1990). Low-birth-weight effects of demographic and socioeconomic variables and prenatal care in Pima County, Arizona. Western Journal of Medicine, 152, 725-728.

Tourangeau, R., and Smith, T. W. (1996). Asking sensitive questions: the impact of data collections mode, question format, and question content. Public Opinion Quarterly, 60, 275-304.

Ventura, S. J., Curtin, S. C., Mathews, T. J. (1998). Teenage births in the United States: National and state trends, 1990-1996. National Vital Statistics System. Hyattsville, MD: National Center for Health Statistics.

Whitehead, N. S., Brogan, D. J., Blackmore-Prince, C., Hill, H. A. (2003). Correlates of experiencing life events just before or during pregnancy. Journal of Psychosomatic Obstetrics and Gynecology, 24, 77-86. 
Whitehead, N. S., Hill, H. A., Brogan, D. J., Blackmore-Prince, C. (2002). Exploration of threshold analysis in the relation between stressful life events and preterm delivery. American Journal of Epidemiology, 155, 117-124.

\title{
Acknowledgements
}

We wish to thank Ms. Marisa Martin from the Family Health Service Division for her assistance as Hawai i PRAMS Data Manager, George Lin and Caryn Tottori from the Office of Health Status Monitoring for their assistance selecting the live birth sample, as well as the rest of the Hawai i PRAMS team. This project was made possible by a Cooperative Agreement (U50/CCU917125-05) from the Division of Reproductive Health, National Center for Chronic Disease Prevention and Health Promotion, Centers for Disease Control and Prevention and through the Fellowship support of Nighat Quadri by the Association of Teachers of Preventive Medicine.

\author{
Author Information \\ Cheryl B. Prince, Ph.D., M.P.H., M.S.N.* \\ Hawai`i Department of Health \\ Family Health Services Division \\ 3652 Kilauea Avenue \\ Honolulu, HI 96816 \\ Limin Song, M.P.H. \\ Hawai`i Department of Health \\ Family Health Services Division \\ Maternal and Child Health Branch \\ 741-A Sunset Avenue \\ Honolulu, HI 96816 \\ Nighat Quadri, M.P.H., M.S. \\ Hawai i Department of Health \\ Family Health Services Division \\ 235 Beretania Avenue \\ Honolulu, HI 96813 \\ Kathleen Kromer Baker, Ph.D., M.S. \\ Hawai i Department of Health \\ Office of Health Status Monitoring \\ 1250 Punchbowl Street \\ Honolulu, HI 96813 \\ *Corresponding author
}

